\title{
Research on the Relationship between Parental Rearing Patterns and Junior High School Students' Emotional Adjustment Strategies
}

\author{
Jie Yin ${ }^{1}$, Fanggui Tang ${ }^{1}$, Mei Liu ${ }^{1}$ \\ ${ }^{1}$ Hengyang Normal University, School of Education Science, Hengyang, Hunan, 421002
}

Keywords: Parenting Style; Junior High School Students; Emotional Adjustment Strategies

\begin{abstract}
Objective: To understand the relationship between parenting style and junior high school students' emotional adjustment strategies. Methods: A questionnaire survey was conducted on 300 junior high school students from Hengyang Boya School by using the Parental Rearing Rating Scale revised by Yue Dongmei et al. and the Cognitive Emotion Regulation Strategy Scale revised by Dong Guangheng and others. The data were statistically analyzed. Results (1) The parenting styles used by the parents of junior high school students were emotional warmth and understanding. There were differences in parenting styles of junior high school students of different genders and grades $(\mathrm{P}<0.05, \mathrm{t}=3.681)$; (2) The mood adjustment strategies of junior high school students were overally positive. There were significant differences in the emotional adjustment strategies of junior high school students of different genders and grades $(\mathrm{P}<0.05, \mathrm{t}=-2.914)$, and there was no difference in whether or not the only child $(\mathrm{P}>0.05)$. (3) There is a significant correlation between parenting style and junior high school students' emotional adjustment strategies. Conclusions: (1) Parents' parenting styles of junior high school students adopt more emotional warmth and understanding of parenting styles, but they still need further adjustment in the use of other parenting styles; (2) The junior high school students' emotional adjustment strategies are positive overall. The problems are mainly in contemplation and self-blame; (3) there is a correlation between parenting style and junior high school students' emotional adjustment strategies.
\end{abstract}

\section{Introduction}

The junior high school stage is a key period for the individual's physical and mental development. Children at this stage are not suitable for the development of all aspects of body and mind. The emotional state is extremely unstable, and various conflicts and problems are easily caused by emotional changes. If an individual is in an uncomfortable state for a long time, his physical and mental health will be adversely affected. Among the many factors affecting the emotional regulation of junior high school students, family factors, especially parenting styles, play the most important role. This study intends to investigate the relationship between parenting style and the mood of junior high school students and the relationship between them. The results of the study provide a reference for parents to adjust their parenting style, promote positive interaction between parents and children, and finally help junior high school students. Improve personality development.

\section{Research Design}

\subsection{Sample}

Table 1 Sample demographic data $(n=276)$

\begin{tabular}{llll}
\hline & Sample variable & Frequency & percentage \\
\hline gender & male & 139 & $50.36 \%$ \\
& Female & 137 & $49.64 \%$ \\
grade & First grade & 91 & $32.97 \%$ \\
& Second grade & 102 & $36.96 \%$ \\
\multirow{3}{*}{ Whether it is only } & Third grade & 83 & $30.07 \%$ \\
& Yes & 93 & $33.70 \%$ \\
& No & 183 & $66.30 \%$ \\
\hline
\end{tabular}


In this study, students from the first to the third day of the Boya School in Hengyang City were selected for the study. A total of 300 questionnaires were produced and issued, and 276 valid questionnaires were returned. See Table 1 for details:

\subsection{Tools}

Parental Parenting Rating Scale. The Parental Rearing Style Evaluation Scale (EMBU) was prepared by C. Perris, Department of Psychiatry, Umea University, Sweden, and revised by the Chinese version of Yue Dongmei et al. The scale has good reliability and validity. It includes 66 questions. According to the 1-4 level score standard, it is divided into never, occasionally, often, and always four levels.

Cognitive Emotion Regulation Strategy Scale. The revised Chinese version of the Cognitive Emotional Strategy Questionnaire (CERQ) is Dong Guangheng, Zhu Yanxin, Yang Lizhu, etc. The questionnaire consists of 18 items in 9 dimensions. According to the test, the reliability of this questionnaire is good.

Procedure. This study used SPSS16.0 software for data processing and analysis, mainly for descriptive statistical analysis, independent sample t-test and correlation analysis.

\section{Research Results}

\subsection{Analysis of the Status Quo of Parenting Style}

Overall situation of parenting style

Table 2 Overall situation of parenting style

\begin{tabular}{lllll}
\hline & \multicolumn{3}{l}{ father } & mother \\
\cline { 2 - 5 } & $\mathrm{M}$ & $\mathrm{SD}$ & $\mathrm{M}$ & $\mathrm{SD}$ \\
\hline Emotional warmth, & 54.25 & 11.004 & 56.49 & 11.765 \\
understanding & & & & \\
Severe punishment & 17.9 & 5.987 & 12.56 & 4.916 \\
Excessive interference & 16.03 & 4.278 & 32.66 & 8.523 \\
Preference & 5.8 & 4.913 & 5.82 & 4.742 \\
Refuse to deny & 8.61 & 3.025 & 12.04 & 4.618 \\
Overprotection & 9.45 & 3.026 & & \\
\hline
\end{tabular}

It can be seen from Table 2 that the scores of parenting styles of junior high school students from high to low are the mother's emotional warm understanding, the father's emotional warm understanding, the mother's excessive interference excessive protection, the father's severe punishment, the father's excessive interference, the mother's severe punishment, the mother's refusal to deny, The father was overprotected, the father refused to deny, the mother preferred the subject, and the father preferred the subject. Parents have the highest average value in the emotional warmth dimension, indicating that emotional warmth is the most upbringing method adopted by junior high school parents.

Comparison of differences in parental education methods in demographic variables

(1) Gender differences in parenting styles of junior high school students

Table 3 Gender differences in parenting styles of junior high school students

\begin{tabular}{llllll}
\hline & \multicolumn{3}{c}{ Boy $(\mathrm{N}=139)$} & Girl $(\mathrm{N}=137)$ & \multirow{2}{*}{$t$} \\
\cline { 2 - 5 } & $\mathrm{M}$ & $\mathrm{SD}$ & $\mathrm{M}$ & $\mathrm{SD}$ & -0.462 \\
FF1 & 53.94 & 9.943 & 54.55 & 12.014 & $2.185^{*}$ \\
FF2 & 17.86 & 5.943 & 16.30 & 5.949 & $2.224^{*}$ \\
FF3 & 16.59 & 4.034 & 15.45 & 4.454 & $-2.153^{*}$ \\
FF4 & 5.17 & 4.712 & 6.44 & 5.047 & $1.976^{*}$ \\
FF5 & 8.96 & 3.131 & 8.25 & 2.879 & 1.417 \\
FF6 & 9.71 & 3.182 & 9.19 & 2.848 & 1.560 \\
MF1 & 57.58 & 11.820 & 55.38 & 11.647 & 0.573 \\
MF2 & 12.73 & 5.109 & 12.39 & 4.725 & $3.681^{* *}$ \\
MF3 & 34.50 & 8.382 & 30.80 & 8.288 & -1.279 \\
MF4 & 5.46 & 4.695 & 6.19 & 4.778 & -0.339 \\
MF5 & 11.94 & 4.189 & 12.13 & 5.029 & \\
\hline
\end{tabular}


Note 1: FF1: Father's emotional warm understanding, FF2: Father's punishment is severe, FF3: Father interferes excessively with FF4: Father prefers the subject, FF5: Father refuses to deny, FF6: Overprotection, MF1: Mother's emotional warm understanding, MF2: Mother's punishment Severe, MF3: Mother interferes excessively with protection, MF4: Mother prefers the subject, MF5: Mother refuses to deny.

Note $2: * \mathrm{P}<0.05 ; * * \mathrm{P}<0.01 ; * * * \mathrm{P}<0.001$

As shown in Table 3, from the perspective of parental parenting style scores, the father's parenting style is severely punished, excessively interfered, overprotected, denied denial, and favored. According to the mean value, the mother's parenting style is as high as the parenting style. The low order is excessive interference protection, severe punishment, refusal to deny, and preference for subjects. Parents have significant differences in parenting styles for children of different genders $(\mathrm{P}<0.05)$. Parents prefer to use severe punishment, excessive interference protection, and refusal to deny these negative and strict parenting styles. Daughters prefer to adopt emotional warmth and preference.

(2) Analysis of the grade differences of junior high school students in parenting style

Table 4 Analysis of the grade differences of junior high school students in parenting style $(\mathrm{M} \pm \mathrm{SD})$

\begin{tabular}{|c|c|c|c|c|}
\hline & $\begin{array}{l}\text { First } \\
(\mathrm{N}=91)\end{array}$ & $\begin{array}{l}\text { Second } \\
(\mathrm{N}=102)\end{array}$ & $\begin{array}{ll}\text { Third } & \text { grade } \\
(\mathrm{N}=83) & \end{array}$ & $F$ \\
\hline FF1 & $55.00 \pm 11.707$ & $54.26 \pm 10.865$ & $53.40 \pm 10.436$ & 0.459 \\
\hline FF2 & $18.47 \pm 7.267$ & $15.99 \pm 4.462$ & $16.92 \pm 5.836$ & $4.283^{*}$ \\
\hline FF3 & $16.33 \pm 4.933$ & $15.99 \pm 3.957$ & $16.33 \pm 3.854$ & 1.176 \\
\hline FF4 & $5.64 \pm 5.577$ & $6.08 \pm 4.769$ & $5.64 \pm 4.318$ & 0.257 \\
\hline FF5 & $9.43 \pm 3.670$ & $8.65 \pm 2.635$ & $7.66 \pm 2.385$ & $7.777^{*}$ \\
\hline FF6 & $11.01 \pm 2.987$ & $9.29 \pm 2.781$ & $7.93 \pm 2.512$ & $27.054^{* *}$ \\
\hline MF1 & $56.58 \pm 11.195$ & $55.06 \pm 13.608$ & $58.14 \pm 9.656$ & 1.585 \\
\hline MF2 & $14.48 \pm 5.982$ & $11.73 \pm 4.266$ & $11.47 \pm 3.630$ & $11.258^{* *}$ \\
\hline MF3 & $35.16 \pm 7.993$ & $33.00 \pm 7.629$ & $29.51 \pm 9.200$ & $10.353^{* *}$ \\
\hline MF4 & $5.54 \pm 5.321$ & $5.92 \pm 4.507$ & $6.01 \pm 4.380$ & 0.250 \\
\hline MF5 & $13.44 \pm 4.980$ & $12.28 \pm 4.597$ & $10.19 \pm 3.542$ & $21.498^{* *}$ \\
\hline
\end{tabular}

Note: $* \mathrm{P}<0.05 ; * * \mathrm{P}<0.01 ; * * * \mathrm{P}<0.001$

As shown in Table 4, junior high school students of different grades have significant differences in the punishment of severe punishment, refusal to deny, and excessive protection; the mother's severe punishment, refusal to deny, and excessive interference protection $(\mathrm{P}<0.05)$. In order to further explore the difference, the LSD method was used to compare multiple means between groups. When the $\mathrm{P}$ value was less than 0.05 , there was a significant difference. The scores of the first grade in each dimension were higher than those in the second and third grades. There was a significant difference $(\mathrm{P}<0.05)$.

\subsection{Analysis of the Status Quo of Junior High School Students' Emotional Adjustment Strategies}

Overall situation of junior high school students' emotional adjustment strategies

Table 5 Overall situation of junior high school students' emotional adjustment strategies

\begin{tabular}{lll}
\hline & $\mathrm{M}$ & $\mathrm{SD}$ \\
\hline Self-blame & 5.05 & 2.436 \\
accept & 6.05 & 2.304 \\
meditation & 5.47 & 2.165 \\
Refocus & 6.46 & 2.010 \\
Concerned plan & 7.17 & 1.975 \\
Active re-evaluation & 6.66 & 2.018 \\
Rational analysis & 7.07 & 2.170 \\
Catastrophic & 4.81 & 2.126 \\
Blaming others & 4.13 & 1.727 \\
\hline
\end{tabular}


The Emotional Adjustment Strategy Scale used in this study used a 1-5 rating. The higher the scores in each dimension, the higher the frequency with which the individual uses this emotional adjustment strategy, because the individual will form a solid choice in the choice of emotional adjustment strategies. Cognition, in this cognitive guidance, choose strategies, unless you change your cognition, you will always follow the same strategy choices. It can be seen from Table 5 that the emotional adjustment strategies of junior high school students are positive overall, and the problems are mainly contemplative and self-censor. The frequency of junior high school students' use of emotional adjustment strategies is followed by planning, rational analysis, positive re-evaluation, re-focusing, accepting facts, contemplation, self-blame, catastrophe, and blaming others.

Differences in the demographic variables of junior high school students' emotional adjustment strategies

(1) Analysis of gender differences in emotion adjustment strategies of junior high school students

Table 6 Gender Difference Analysis of Junior Middle School Students' Emotional Adjustment Strategies

\begin{tabular}{|c|c|c|c|c|c|}
\hline & \multicolumn{2}{|c|}{ Boy $(n=139)$} & \multicolumn{2}{|c|}{ Girl（n=137） } & \multirow[b]{2}{*}{$t$} \\
\hline & $\mathrm{M}$ & SD & $\mathrm{M}$ & SD & \\
\hline Self-blame & 5.01 & 2.537 & 5.08 & 2.339 & -.224 \\
\hline accept & 5.71 & 2.250 & 6.39 & 2.315 & $-2.508^{*}$ \\
\hline $\begin{array}{l}\text { Reflective } \\
\text { self }\end{array}$ & 5.34 & 2.128 & 5.61 & 2.200 & -1.055 \\
\hline $\begin{array}{l}\text { Active } \\
\text { attention }\end{array}$ & 6.50 & 1.839 & 6.42 & 2.175 & .331 \\
\hline $\begin{array}{l}\text { Concerned } \\
\text { plan }\end{array}$ & 6.83 & 1.911 & 7.51 & 1.986 & $-2.914^{* *}$ \\
\hline $\begin{array}{l}\text { Active } \\
\text { re-evaluation }\end{array}$ & 6.51 & 2.051 & 6.80 & 1.981 & -1.203 \\
\hline $\begin{array}{l}\text { Rational } \\
\text { analysis }\end{array}$ & 7.09 & 2.129 & 7.05 & 2.217 & .162 \\
\hline Catastrophic & 4.85 & 2.126 & 4.77 & 2.133 & .322 \\
\hline $\begin{array}{l}\text { Blaming } \\
\text { others }\end{array}$ & 4.25 & 1.703 & 4.00 & 1.749 & 1.212 \\
\hline
\end{tabular}

Note: $* \mathrm{P}<0.05 ; * * \mathrm{P}<0.01 ; * * * \mathrm{P}<0.001$

As shown in Table 6, there is no significant difference in the dimensions of self-censorship, self-report, positive concern, positive re-evaluation, catastrophe, rational analysis, and blame on others in the emotional adjustment strategy $(\mathrm{P}>0.05)$, but in accepting and paying attention There were significant differences in the two dimensions of the plan $(\mathrm{P}<0.05)$, and the scores of girls in the acceptance and attention plan were greater than those of the boys.

(2) Difference analysis of junior high school students' emotion adjustment strategies at grade level

As shown in Table 7, except for the differences in the dimensions of acceptance, positive reassessment, and rational analysis, there are differences in the other levels of the mood adjustment strategy at different levels of $P$ values less than 0.05 . .

Among them, in self-blame, the second day is higher than the first one and the third day $(\mathrm{P}<0.001)$, and there is no significant difference between the first day and the third day. On the self-reflection, the second day was higher than the first one $(\mathrm{P}<0.05)$, and the first and second grades were higher than the first grade $(\mathrm{P}<0.001)$. In the positive attention, the first day was higher than the second day $(\mathrm{P}<0.05)$, and there was no significant difference between the other grades. In the plan of concern, the second day was higher than the first day $(\mathrm{P}<0.05)$, and there was no significant difference between the other grades. In terms of catastrophe, the first and second grades were higher than the third grade $(\mathrm{P}<0.001)$, and there was no significant difference between the first and second grades. In blaming others, the first and second grades were higher than the third grade $(\mathrm{P}<0.001)$, and there was no significant difference between the first and second grades. 
Table 7 Difference analysis of junior high school students' emotion adjustment strategies at grade level

\begin{tabular}{|c|c|c|c|c|c|}
\hline & grade & Mean & $\begin{array}{l}\text { Standard } \\
\text { deviation }\end{array}$ & $\mathrm{F}$ & LSD \\
\hline \multirow{3}{*}{ Self-blame } & First grade & 4.53 & 2.549 & & \\
\hline & Second grade & 6.21 & 2.172 & $21.498^{*}$ & (2)> (1)(3) \\
\hline & Third grade & 4.19 & 2.063 & & \\
\hline & First grade & 5.73 & 2.526 & & \\
\hline \multirow[t]{3}{*}{ accept } & Second grade & 6.19 & 2.156 & 1.335 & 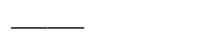 \\
\hline & Third grade & 6.23 & 2.216 & & \\
\hline & First grade & 5.58 & 2.226 & & (2)> (1) (3) \\
\hline \multirow[t]{3}{*}{ Reflective self } & Second grade & 6.26 & 1.975 & $19.787^{*}$ & (1) $>$ (3) \\
\hline & Third grade & 4.39 & 1. 866 & & \\
\hline & First grade & 6.85 & 2.097 & & \\
\hline \multirow[t]{3}{*}{ Refocus } & Second grade & 6.20 & 1.925 & $2.668^{*}$ & (1) $>$ (2) \\
\hline & Third grade & 6.37 & 1.974 & & \\
\hline & First grade & 6.78 & 2.075 & & \\
\hline \multirow[t]{3}{*}{ Concerned plan } & Second grade & 7.61 & 1.736 & $4.552^{*}$ & (2) $>$ (1) \\
\hline & Third grade & 7.05 & 2.054 & & \\
\hline & First grade & 6.22 & 2.102 & & \\
\hline \multirow{3}{*}{$\begin{array}{l}\text { Active } \\
\text { re-evaluation }\end{array}$} & Second grade & 7.04 & 2.000 & 4.052 & - \\
\hline & Third grade & 6.66 & 1.869 & & \\
\hline & First grade & 7.13 & 1.996 & & \\
\hline \multirow{3}{*}{$\begin{array}{l}\text { Rational } \\
\text { analysis }\end{array}$} & Second grade & 6.95 & 2.310 & .255 & \\
\hline & Third grade & 7.16 & 2.195 & & \\
\hline & First grade & 5.30 & 2.041 & & (1) $\square \square>$ (3) \\
\hline \multirow[t]{3}{*}{ Catastrophic } & Second grade & 4.91 & 2.225 & $6.847^{*}$ & (2) $>$ (3) \\
\hline & Third grade & 4.14 & 1.939 & & \\
\hline & First grade & 4.40 & 1.807 & & (1) $\square \square>$ (3) \\
\hline \multirow[t]{2}{*}{ Blaming others } & Second grade & 4.42 & 1.720 & $9.095^{*}$ & (2) $>$ (3) \\
\hline & Third grade & 3.47 & 1.468 & & \\
\hline
\end{tabular}

Note: $* \mathrm{P}<0.05 ; * * \mathrm{P}<0.01 ; * * * \mathrm{P}<0.001$

(3) Analysis of the differences in the emotion adjustment strategies of junior high school students in the only child

Table 8 Analysis of the differences in the emotion adjustment strategies of junior high school students in the only child

\begin{tabular}{|c|c|c|c|c|c|}
\hline & \multicolumn{2}{|c|}{ Only child $(n=93)$} & \multicolumn{2}{|c|}{ Non-only child $(\mathrm{n}=183)$} & \multirow[b]{2}{*}{$t$} \\
\hline & $\mathrm{M}$ & SD & $\mathrm{M}$ & SD & \\
\hline Self-blame & 4.67 & 2.271 & 5.24 & 2.500 & -1.858 \\
\hline accept & 6.01 & 2.144 & 6.07 & 2.387 & -0.186 \\
\hline Reflective self & 5.42 & 2.133 & 5.50 & 2.186 & -0.302 \\
\hline Refocus & 6.62 & 2.074 & 6.38 & 1.977 & 0.942 \\
\hline Concerned plan & 7.02 & 1.939 & 7.24 & 1.994 & -0.870 \\
\hline $\begin{array}{l}\text { Active } \\
\text { re-evaluation }\end{array}$ & 6.55 & 1.897 & 6.71 & 2.080 & -0.630 \\
\hline $\begin{array}{l}\text { Rational } \\
\text { analysis }\end{array}$ & 7.05 & 1.902 & 7.08 & 2.299 & -0.108 \\
\hline Catastrophic & 4.76 & 1.890 & 4.83 & 2.241 & -0.248 \\
\hline Blame others & 4.15 & 1.763 & 4.11 & 1.714 & 0.162 \\
\hline
\end{tabular}

Note: $* \mathrm{P}<0.05 ; * * \mathrm{P}<0.01 ; * * * \mathrm{P}<0.001$

As shown in Table 8, there was no statistical significance at the significant level of $\mathrm{P}$ value greater than 0.05 , that is, there was no difference between the only child and the non-only child in each dimension of the emotion regulation strategy $(\mathrm{P}>0.05)$. 
Correlation Analysis between Parental Rearing Patterns and Junior Middle School Students' Emotional Adjustment Strategies

Table 9 Correlation analysis between father's parenting style and junior high school students' emotional adjustment strategies

\begin{tabular}{|c|c|c|c|c|c|c|}
\hline & FF1 & FF2 & FF3 & FF4 & FF5 & FF6 \\
\hline Self-blame & 0.026 & 0.033 & 0.036 & 0.087 & 0.066 & 0.032 \\
\hline accept & 0.025 & 0.014 & 0.011 & -0.013 & -0.011 & $-0.095^{*}$ \\
\hline Reflective self & 0.075 & 0.053 & 0.064 & 0.072 & 0.033 & $0.099^{*}$ \\
\hline Refocus & 0.061 & -0.032 & -0.068 & -0.041 & -0.061 & -0.049 \\
\hline $\begin{array}{l}\text { Concerned } \\
\text { plan }\end{array}$ & 0.023 & -0.042 & -0.034 & 0.042 & 0.015 & -0.067 \\
\hline $\begin{array}{l}\text { Active } \\
\text { re-evaluation }\end{array}$ & 0.072 & -0.018 & 0.038 & 0.36 & -0.040 & $-0.107^{*}$ \\
\hline $\begin{array}{l}\text { Rational } \\
\text { analysis }\end{array}$ & 0.053 & -0.066 & -0.014 & 0.064 & $-0.091^{*}$ & -0.078 \\
\hline Catastrophic & -0.010 & 0.073 & 0.041 & 0.021 & 0.079 & 0.051 \\
\hline Blame others & -0.45 & 0.088 & 0.018 & 0.07 & $0.113^{*}$ & $0.102^{*}$ \\
\hline
\end{tabular}

Note: $* \mathrm{P}<0.05 ; * * \mathrm{P}<0.01 ; * * * \mathrm{P}<0.001$

Table 9 shows that there is a significant negative correlation between acceptance, reflection, positive re-evaluation, blame and overprotection in the emotional adjustment strategies of junior high school students $(\mathrm{P}<0.05)$; there is a significant negative correlation between rational analysis and father's refusal to deny. $(\mathrm{P}<0.05)$; there was a significant positive correlation between the blame of others and the father's refusal to deny $(\mathrm{P}<0.05)$.

Table 10 Correlation between maternal parenting style and junior high school students' emotional adjustment strategies

\begin{tabular}{llllll}
\hline & MF1 & MF2 & MF3 & MF4 & MF5 \\
\hline Self-blame & -0.025 & 0.035 & -0.026 & 0.062 & 0.064 \\
accept & 0.016 & -0.066 & $-0.096^{*}$ & -0.018 & -0.036 \\
Reflective self & -0.044 & 0.077 & 0.014 & 0.035 & $0.112^{*}$ \\
Active attention & $0.10^{1^{*}}$ & $-0.096^{*}$ & -0.074 & 0.000 & -0.049 \\
$\begin{array}{l}\text { Concerned plan } \\
\text { Active }\end{array}$ & -0.016 & -0.035 & $-0.094^{*}$ & 0.033 & 0.018 \\
$\begin{array}{l}\text { re-evaluation } \\
\text { Rational }\end{array}$ & 0.032 & -0.056 & -0.056 & 0.034 & -0.054 \\
$\begin{array}{l}\text { analysis } \\
\text { Catastrophic }\end{array}$ & 0.038 & -0.082 & -0.011 & & \\
Blame others & -0.062 & $0.066^{*}$ & $0.093^{*}$ & 0.073 & -0.068 \\
\hline
\end{tabular}

Note: $* \mathrm{P}<0.05 ; * * \mathrm{P}<0.01 ; * * * \mathrm{P}<0.001$

Table 10 shows that positive concern has a significant positive correlation with mother's emotional warmth $(\mathrm{P}<0.05)$; there is a significant negative correlation between blame and mother's emotional warmth $(\mathrm{P}<0.05)$; re-focus has a significant negative correlation with maternal punishment $(\mathrm{P}<0.05)$. There was a significant positive correlation between the blame of others and the severe punishment of the mother $(\mathrm{P}<0.05)$; there was a significant negative correlation between the acceptance and attention plan and the mother's excessive interference $(\mathrm{P}<0.05)$; there was a significant positive correlation between the blame and the mother's excessive interference $(\mathrm{P}<0.05)$. Contemplation and blame others and the mother refused to deny that there was a significant positive correlation $(\mathrm{P}<0.05)$.

\section{Discussion and Analysis}

\subsection{Discussion and Analysis of Parenting Styles}

The results of the study show that parents use the most emotional and warm understanding of parenting, which can provide children with a warm and harmonious family environment, which has 
a positive impact on all aspects of children's development.

There are significant differences in the scores of junior high school students of different genders, such as severe punishment by father, father's refusal to deny, father's preference for test, and excessive interference of mothers. This may be because parents have different expectations for the development of children of different genders, so the specific method of parenting It will be different. Parents expect boys to be taller than girls. Usually, boys are punished and rejected to teach them. When they are treated, parents will pay more attention to their living habits, to protect girls and protect girls, and to More interference. In the father's excessive interference, father's excessive protection, mother's preference, mother's severe punishment, the mother refused to deny the scores of the factors, there is no significant difference, indicating that the father treats the children in a protective form, caring for their growth, while the parents treat the only child, or multiple births. Children can try to be too biased.

Junior high school students of different grades have significant differences in the dimensions of father's severe punishment, refusal to deny, overprotection, severe punishment of mothers, refusal to deny, and excessive interference protection, and the scores of the first grade in each dimension are higher than those of the second and third grades. grade. The first-year students have just entered the new stage of study, and all disciplines need to lay a solid foundation. Plus the first-year children are more rebellious and prone to disasters, so parents will be more strict and strict in their study and life. It will also interfere with more and implement mandatory protection.

\subsection{Discussion and Analysis of Junior Middle School Students' Emotional Adjustment Strategie}

The results show that junior high school students use more emotional adjustment strategies, such as planning, rational analysis, positive re-evaluation and other positive strategies. The junior high school stage is the period of individual social development, their psychological level is improving, and all aspects of body and mind they are also beginning to become adults. They are eager to become strong and mature. They no longer rely on the protection of their parents. They gradually understand self-discipline and become long. This desire is the driving force for their continuous efforts, so most of them tend to face bad emotions. The active attention to the plan is the strategy they use the most, which means that the children now have higher requirements for themselves and will try their best to solve the problem. But at the same time, there are also contemplations and blame for themselves. This is related to the current children's stressful learning and heavy academic burden. In the study life, they encounter some setbacks, which are easy to lose confidence and will be negatively considered to be their own reasons.

There are significant differences in acceptance and attention programs among junior high school students of different genders. Girls' scores on acceptance are higher than boys', which is related to the expectations and requirements of society for boys and girls with different gender roles. In life, girls are generally more likely than boys to admit their own inadequacies and mistakes, and they are more likely to meet the needs, while boys are mostly Compared with face, it will not easily give in, so girls score high; in addition, girls may not be calm when they encounter things, but they are generally more careful than boys, and they are more able to make plans to solve problems, so they score higher than boys in the plan. .

Junior high school students of different grades have significant differences in self-blame, self-reflection, active attention, attention to planning, catastrophe, and blame others. Among them, students in the first and second grades score higher than junior high school in disasters and blame others. Students, this may not be strong with the psychological capacity of the first and second day children, do not want to take responsibility, easy to negatively pessimistic or blame others. In self-blame and self-reflection, the scores of the second grade students are higher than those of the first and third grades. Although the children of the second grade have adapted to the junior high school life, the burden of learning is increasing, making them prone to troubles. I still can't look at the problem correctly; in the positive attention, the score in the first grade is the highest, because I just entered junior high school, I don't think too far when I think about the problem, I think it is 
relatively simple, so I can easily turn my attention to something else. In the matter of the second grade, the second grade is higher than the first grade. This is because the students in the second grade have gradually adapted to the life of junior high school. The psychological development is more mature on the basis of the original, and they can learn to make plans and arrange well. The emotional adjustment strategies of junior high school students do not differ in whether they are only children.

\subsection{Analysis of the Relationship between Parenting Style and Emotional Adjustment Strategies}

According to the survey, parents' parenting style is related to the choice of junior high school students' emotional adjustment strategies. First, parents who adopt emotional warmth and understanding parenting style will have stronger psychological endurance when encountering negative events because they can get comfort and support from their parents, and they can choose positive emotional adjustment strategies to adjust their mentality and solve problems more confidently. Secondly, parents use children who are severely punished and refuse to deny parenting. Excessive severe punishment will make children Fear and dare to approach the parents, be cautious and careful, and be perfect. If you fail, you will panic, fear of being punished and lose confidence. And often rejecting and denying the child will affect the child's self-confidence, it is easy to have inferiority, because junior high school the child is born in a critical period of great change in mind and body. The cognition of oneself is not accurate enough. It will be eager to get affirmation and trust from the parents. If the parents are more likely to refuse and distrust, the child will deny and letting yourself go, it will have a negative impact on all aspects of development, and there will be no courage when you encounter it. For responsibility and choose to escape, or attributed to others. In addition, this study shows that most parents adopt excessive parenting and protection, which will make children lack the courage to face problems alone, rely more on their parents or friends, and easily self-centered, regardless of other people's feelings. At the same time, there will be ideas for getting something for nothing. It is more difficult to take the initiative to make plans and solve problems through your own efforts.

Therefore, the best parenting style should be: as a solid backing for the child, give the child a harbor full of love, let the child stop to adjust at any time when tired, and then continue to move forward; take the initiative to approach the child Understand and respect them, choose the appropriate way to communicate with them; at home is not only the mode of getting along with the elders and the younger generations, but also trying to get along with equal friends, which will close the psychological distance, parents as a guide for the children's life. You should give your child a space to explore and free, and develop the child into a good young man who is self-reliant and self-confident. Children who grow up in an atmosphere full of love and understanding are full of self-confidence. They can also adjust their mentality well, look at the gains and losses correctly, and have the ability to solve the problems they encounter.

\section{Conclusion Recommendations}

\subsection{Conclusion}

(1) According to the study, the current parenting style of junior high school students is more about using emotional warmth and understanding, but there are significant differences in gender and grade. Parents treat their sons more with harsh punishment, refusal to deny and excessive the parenting style of intervention and protection, and more emotional warmth and understanding for the daughter, and the father generally prefers the daughter.

(2) According to relevant analysis, there is a significant correlation between parenting style and junior high school students' emotional adjustment strategies. Parents adopting emotional warmth and understanding of parenting styles can better help children to choose positive emotional regulation strategies, while parents adopt strict punishment, refusal to deny and excessive interference protection, which will make children choose negative emotional regulation strategies more. 


\subsection{Recommendation}

\subsubsection{Parents should give young people full warmth understanding and care}

In life, parents should not ignore the child's feelings, be patient and pay attention to all aspects of the child; give the child more encouragement and support; try to let go slowly, let the children have the opportunity to exercise to learn to go to independence, give them Enough trust and confidence to experience setbacks and failures; listen to the children's voice, answer positive questions about the child's confusion, and reasonably solve the child's demands.

\subsubsection{Parents should combine expectations and make expectations}

Every child is unique. They are different in personality development. It is not that children with good academic performance are smart. The most important thing to learn is to master the methods of learning and the ability to use them. In education, children are required to develop in the aspects of morality, intelligence, beauty, etc., so I think that parents should educate their children to teach them in accordance with their aptitude, and discover the special features of the children. First, cultivate interest, put forward appropriate expectations, and have the motivation to Improve your child's self-confidence, don't put too much burden on the child, and the process and experience are the most important. Adolescent children will have some physical and psychological changes, easy to do some impulsive things or have some rebellious behavior, parents should understand and patiently groom. In learning, don't set the child's goal too high, give the child a slowly rising space, let the children set their own learning goals and plans according to the actual situation, and take every step in a down-to-earth manner, not giving up and laying a solid foundation. Cultivate a child's positive attitude of optimism and correctness, and correctly treat the gains and losses.

\subsubsection{Parents should learn to let go}

Children who enter adolescence begin to realize their growth and feel that they have grown up. They can think independently and make some choices. What parents should do is to be a solid backing for their children, neither in learning nor in life. Excessive concerns that children will encounter obstacles and failures, excessive interference and protection will affect the child's choice of appropriate emotional regulation strategies. If you have not experienced the wind and rain, how can you see the rainbow? If you want to grow up, you must learn to be independent. Only when you have enough strong psychological endurance can learn to let go, so that children can be more confident and self-reliant.

\section{Acknowledgements}

Fund Project: 1) Hunan Provincial Philosophy and Social Science Fund Project "Study on the Cultivation of Positive Psychological Quality of Teenagers in the Sub-health Family Environment of Hunan Province", 15YBA051

2) Research topic of ideological and political education in colleges and universities in Hunan Province: An Empirical Study on the Cultivation and Improvement of Psychological Capital of Poor College Students___ Taking Hengyang Area as an Example 16F09

\section{References}

[1] Nancy Darling \& Laurence steinbery 1 Parenting style as context: An Integvative Model 1 Psychological Bulletin, 1993: 113.

[2] Gu Mingyuan, Dictionary of Education. Shanghai Education Press, 1991, 12, 668.

[3] Master Jc. strategies and mechanisms for the personal and social control of emotion. The development of emotion regulation and dysregulation, 1991: 182-207.

[4] Jiang Award. Research on the relationship between parenting style and adolescent behavior problems [J]. Journal of Health Psychology, 2004, 01: 72-74. 
[5] Fang Ping, Xiong Duanqin, Guo Chunyan. Research on the Influence of Parental Rearing Patterns on Children's Academic Achievements[J]. Psychological Science, 2003, (1): 78-81. 